\title{
Morfología funcional \\ en Cefalópodos y Trilobites
}

Simón Benguigui Levy

El presente trabajo pretende hacer referencia a un sucinto estudio sobre la morfología funcional en los Cefalópodos y Trilobites.

Primeramente se hará referencia resumidamente a la anatomía de estos organismos, para una mejor comprensión de la funcionalidad de la forma, para pasar posteriormente al estudio de la morfología funcional propiamente dicha.

\section{Cefalopodos}

Estos organismos tiene simetría bilateral y su cuerpo es elongado. En la parte anterior está la cabeza, provista de grandes ojos y con una boca rodeada de una corona de tentáculos. Detrás de la cabeza y en forma de surco está la masa visceral, y ventralmente el hiponomo y cavidad branquial, que se encuentra completamente evuelta por el manto, el cual se prolonga posteriormente por el cordón sifonal.

Los ojos están bien desarrollados en muchos coleóideos sin embargo en el Nautilus aparecen como dos agujeros primitivos, teniendo retina pero careciendo de iris y córnea y apareciendo rellenos de agua.

La superficie dorsal de la cabeza aparece protegida por un grueso y endurecido escudo, como podemos observar en el Nautilus.

El pie de los moluscos ancestrales está representado en los cefalópodos por a Hiponomo. Una natación rápida es posible como resultado de la expulsión violenta del agua por pulsaciones del hiponomo (caso del Nautilus) o por potentes contracciones del manto muscular (resto de los cefalópodos vivientes).

El manto también contiene un Osfradium, situado debajo de las branquias. Estos órganos han sido interpretados como quimioreceptores, también como un órgano táctil, cuya misión principal sería estimar la cantidad de sedimentos que entrarían en la cavidad paleal.

El canal alimentario no se extiende de polo a polo sino que forma un bucle, apareciendo la boca y el ano en posición más o menos anterior. La cavidad bucal tiene dientes.

El corazón está encerrado en un pericardio, tiene un ventrículo mediano y muchas auriculas. El ventrículo bombea la sangre al cuerpo a través de las aortas anterior y posterior, las cuales se ramifican en muchos sistemas arteriales. 
Los sexos están separados y los animales son ovíparos, en algunos el dimorfismo sexual es sobresaliente. Las formas de ombligo abierto se denominan evolutas y las que lo tienen cerrado son las involutas.

Todas las características mencionadas corresponden a los cefalópodos vivientes actualmente.

\section{Morfología funcional}

\section{Sección de espira y enrrollamiento}

La sección es ovalada y todas las curvas tienen el mismo periodo con lo cual se economiza concha y se incrementa la estabilidad mediante la separación de los centros de gravedad. Las secciones ojivales son simples modificaciones de las ovaladas, logradas por omisión de la parte central de las curvas. Geométricamente, se pueden derivar una serie de formas por variación de la elongación y solapamiento lateral. Las diferencias funcionales entre estas formas y sus modificaciones en la actualidad son mal conocidas, y deben ser estudiadas en conjunto con otros factores como: enrollamiento, razón de expansión e incluso ornamentación.

Las modificaciones de la sección de la espira en los adultos se manifiestan por redondeamiento y desenrrollamiento del cuerpo en grado variable. Estas modificaciones son más patentes en las microconchas así como en las muy globulosas y en las oxiconas comprimidas. El ombligo se arruga rápidamente y, a menudo, resulta un enrrollamiento elíptico y la sección llega a ser ovalada. Como resultado baja el centro de gravedad, produciéndose un incremento enla estabilidad y una mayor aerodinamicidad en las conchas globulosas. Por el contrario en las conchas grandes, macroconchas, las modificaciones son menores y mas graduales, sobre todo en las formas oxiconas,

Es posible que el desarrollo de una pared umbilical esté relacionado con la unión de los músculos retractores, y probablemente la aerodinamicidad se vea incrementada por la reducción del tamaño del ombligo.

\section{Ornamentación}

El cuerpo es aproximadamente una bóveda, y las costillas sirven para reforzarlo, pero con un gasto minimo de carbonato cálcico y un mínimo sobrepeso. Todo esto se consigue con una costulación transversal.

Las costillas son pliegues de las paredes de la concha girando de modo más o menos paralelo a las líneas de crecimiento, y suelen ser interpretadas como refuerzos de la relativamente fina concha, o como protección contra los choques con el fondo rocoso marino en aguas turbulentas $y / o$ ataque de pequeños predadores.

Se ha investigado también la posibilidad de que en ciertas formas la costulación decrezca bajo condiciones de flujo turbulento. Otra de las explicaciones es que sirvieran de camuflaje. 
Mientras la dirección general de las costillas puede ser explicada por el contorno del peristoma, no está todavía clara la funcionalidad de la división en primarias y secundarias. La interrupción medio-ventral de la costulación probablemente sirve para una mejor unión del sifón.

Los tubérculos, sobre todo los laterales y las espinas ventrolaterales, casi seguramente funcionaban como protección contra los depredadores. También servían para estabilizar al animal.

Las variaciones intraespecíficas de la ornamentación fueron frecuentemente tan fuertes que su función podria haber sido esencial para la supervivencia, o incluso marcadamente selectivas. Las espinas podrían estar presentes o ausentes y las costillas variar mucho en densidad y solidez.

\section{Quilla}

Aparacen a menudo, pero no siempre. Están asociadas a conchas comprimidas 0 al menos aplanadas. Se cree que improvisaban aerodinamicidad y podrian posiblemente ayudar al animal a regular su hundimiento en la arena blanda o barro. También funcionarían como medio de protección, sobre todo del sifón, contra depredadores y daño por impacto con obstáculos. Al igual que en los tubérculos, el desarrollo de un suelo separado parece estar muy relacionado con la altura, economizando concha en quillas prominentes y preservando la fuerza ascensional o elasticidad.

\section{Apertura}

Las modificaciones morfológicas de la apertura de la concha han atraído la anteción, recientemente, en estudios de dimorfismo sexual.

El engrosamiento de la concha debido a secreción (engrosamiento peristomal) continúa después de que el crecimiento longitudinal ha cesado. Este engrosamiento da protección contra depredadores e impactos.

La función de las diversas formas de apertura no es del todo conocida. Se dan todos los grados de apertura, desde los indetectables a los mas pronunciados, y a menudo hay concurrencia con la diferenciación de sexos.

Septos. Sutura. Grosor de los septos

De acuerdo con los estudios de Mutvei (1967) y Erben et Al. (1969) el septo de los ammonóideos consiste en una sencilla capa nacarada, curvada a ambos lados por las membranas conchales. Sólo hay unas pocas medidas de espesor válidas, y estas dan información sobre el estado de crecimiento (excepto el diámetro).

El engrosamiento de los septos en los adultos y su aproximación se explican por una deceleración o cese del crecimiento normal de la pared, acompa- 
En los tipos flotantes y de libre natación, los ojos suelen estar situados cerca del margen del escudo capital. Cuando los ojos se separan del margen, nos hace pensar en una mudanza de hábitos pelágicos a bentónicos.

Ciertos trilobites como Ampyx, están dotados de espinas largas, que pueden haber hecho desplazarse el centro de gravedad, sirviendo de balancines, o haber actuado como quillas. La presencia de tales espinas serviría como defensa para el animal.

El pigidio funcionaria como un poderoso órgano propulsor permitiendo al trilobite nadar mucho más rápidamente de lo que le permitían sus patas. Además, un golpe seco de la cola hacia abajo y hacia adelante, serviría para que el animal saliese disparado hacia atrás al encontrarse con algún peligro.

\section{BIBLIOGRAFIA}

MOOR, R.C. (1959): "Trataise on Invertebrate Paleontology". Vol O.- "Arthropoda"' I, pp. 2-29; Vol. K.- "Mollusca". III pp. 4-13. Geological Society of America and University of Kansas Press.

SWINNERTON, H.H. (1961): “Elementos de Paleontologia". Editorial Omega. PP. 188-207, 244-255. Madrid.

WESTERMANN, G.E.G. (1971): "From, Structure and Function of Shell and Siphuncle in Coiled Mesozoic Ammonoids". Life Sciences Contributions Royal Ontario Museum. N. ${ }^{\circ}$ 72, pp 4-34. Toronto. 